Medical Social Department, St. Helen's Hospital, Hastings, Sussex

Dear Dr. Hunter,

Dr. Irvine has asked me to see these old ladies and I visited them yesterday. As you know, Mrs. Y.Z. has only been in this area for six months and lived in London for $\mathbf{4 0}$ years. Her memory has been failing for some time but she managed at home with increasing help from her husband until his sudden death. She has some insight into her problems and told me that she stayed in bed partly to keep warm, and partly to dream of "the dear dead days." I think she may also be depressed. Although the sisters are fond of each other, Miss A.B. had no love for her brother-in-law, feeling that her sister married beneath her and she is impatient with the sister's grieving.

Financially, too, they are in a mess. Mrs. Y.Z. is still paying the rent of the flat in London. Miss A.B.'s domestic expenses have escalated, especially for heating and laundry. She complains that she cannot keep her sister warm.

I think it will be recessary to admit Mrs. Y.Z. to the geriatric unit for rehabilitation and to relieve domestic tensions. While she is here Miss A.B. will spend a few days in London to clear the flat and terminate the tenancy. I will apply for a Supplementary Pension for Mrs. Y.Z., and if she can get the Attendance Allowance as well they will manage comfortably.

There will be a bed for Mrs. Y.Z. on Wednesday. Would you be kind enough to send her to Wand 6 on that day.

\section{St. Helen's Hospital, Hastings, Sussex}

\section{Dear Graham,}

Mrs. Y.Z. is being discharged today after a month in the geriatric unit. We found her very inert and apathetic when she first arrived in the wand. My registrar was struck by her slow pulse and dry skin and by her rather croaky voice. He instituted some investigations for hypothyroidism and found that her serum protein-bound-iodine level was 1.8 micrograms $/ 100 \mathrm{ml}$. Her cholesterol proved to be $580 \mathrm{mg}$ per $100 \mathrm{ml}$ and thyroid antibodies were found in the serum. It it interesting that her sister has a goitre.

We have now been treating her with thyroxine for the past fortnight and she has improved very considerably. She is now ambulant again and continent, but is not yet fully back to normal. Her sister, Miss A.B., is feeling much better and has asked to have her sister home.

It might be helpful if we continue to share the burden with Miss A.B. by having her sister to the day hospital once a week for a time. Some people with mental impairment associated with hypothyroidism do not recover fully and there may be an element of permanent dementia here.

\section{Tamarisk Lodge Surgery, Bexhill-on-Sea, Sussex}

\section{Dear Bobby,}

Miss A.B. and her sister are now wonderfully improved and almost back to normal. Miss A.B. still wears her collar and continues with her vitamin $B_{12}$ injections and is now back to her usual self while her sister's dementia is manageable.

In retrospect, I feel I should have considered myxoedema as a diagnosis for the sister. This is, of course, difficult to spot when one is seeing the patient regularly, especially when they come to the district with a diagnosis of senile dementia. One cannot be too careful before accepting senile dementia as a diagnosis.

\section{Comment by Both Doctors}

Both our patients are now doing well. They illustrate many points in geriatric medicine. Both reveal the impact in old age of multiple diseases. One should seldom be satisfied with a single diagnosis in an elderly person. Brain stem ischaemia associated with cervical spondylosis, atheroma, and kinking of the vertebral arteries is exceedingly common, but the symptoms sometimes improve if the patient will wear a collar. Tingling in the hands and feet is not usually a feature of vertebrobasilar insufficiency and the early changes in the tongue suggested pernicious anaemia. The lesson here is that any patient with a haemoglobin below $11 \mathrm{~g}$ should not be assumed to have an iron-deficiency anaemia. A blood film and indices are necessary and easily performed in the laboratory.

Miss A.B. was at risk after her gastrectomy and should perhaps have had regular follow-up. This is much easier to arrange when the patient remains in the same area and under the same doctor as when she had her operation. Difficulties often arise when such patients move from one area to another.

We attempted to support both these patients with the help of the social services, the day hospital, and a brief social admission. The cases show, however, that social support is inadequate until the patients are assessed medically and given the proper treatment.

\title{
Impressions of Cogwheel
}

\section{A Hospital Junior Doctor}

FROM A SPECIAL CORRESPONDENT

\section{British Medical fournal, 1972, 4, 225-227}

Discussing the divisional system, the first Cogwheel report ${ }^{1}$ said, "The division would include all the consultants and their junior staff and would meet regularly to review its work. . . . In such a system the substantial contribution of junior staff-especially registrars-to the organization of the work could be more fully recognized. One of the present frustrating factors for many capable young doctors is undoubtedly their lack of opportunity to influence the management of their own work in order to improve efficiency."

Indeed, Sir George Godber's working party have given practical form to their concern both for the hospital junior doctors and for the lack of information about them by commissioning and publishing a report on their activities. This book, Organization of the Work of funior Hospital Doctors, ${ }^{2}$ can also be obtained in abbreviated form as All in a Working Day. ${ }^{3}$ The main part of this study investigated the work of 85 doctors in nine hospitals. 847,363 half-minute observations were made of 77,049 individual activities. Thirty-eight doctors 
were in the house officer, senior house officer, registrar, or senior registrar grades in general medicine, 26 in general surgery, and 21 in accident and emergency services. The average total duty time had been found to be 88 hours 15 minutes per week-of which 38 hours 33 minutes were spent actually working. As might be expected this proportion of working time was higher in the house officer grades, becoming less with seniority. Dr. Bridgnorth,* a senior registrar to whom I talked, had been encouraged by the obvious recommendations arising from these data but not by some of the definitions used in the study. $\mathrm{He}$ had also been depressed by the fact that the amount of doctors' time positively identified as training had averaged only seven minutes per week in the accident and emergency departments, 29 minutes per week in general surgery, and $1 \frac{1}{4}$ hours in general medicine. He had agreed with most of the doctors' comments, which generally referred to the apparently trivial matters which together raise or depress the morale of a hospital. Dr. Bridgnorth thought that an active hospital mess could do much to avoid these problems. In particular only two of the hospitals studied in the report had had mess committeees. In some hospitals hospital junior doctors had been invited to nominate representatives to serve on the medical staff committee and similar committees, but this had seldom proved effective.

Despite this apparent lack of enthusiasm for representation at divisional and medical executive committees by many junior doctors, the Cogwheel working party (in their second report ${ }^{4}$ ) were concerned at the failure to include them actively in the Cogwheel structure. But in Dr. Bridgnorth's hospital group the exertions of the junior staff had resulted in all registered doctors being voting members of divisions. The arguments in favour of this had been that the junior doctors would turn up in force only when something serious, such as shortage of nursing staff at night, was under discussion. Otherwise, only a few representatives would appear and not provide much voting power. Dr. Bridgnorth, one of the active junior doctors concerned, said that this had proved to be true. The senior staff had been worried about junior votes when disciplinary matters were under consideration, but during the year of negotiations about introducing Cogwheel the junior staff had agreed to withdraw on these occasions.

\section{Workings of a Division}

Dr. Bridgnorth's own division, anaesthetics, met outside working hours and was attended by a Salmon grade 7 or 8 , an administrator (but the departmental secretary took the minutes), medical assistants, and clinical assistants. One general practitioner belonged to the division but he rarely attended. Of the 24 voting members 15 usually turned up to the monthly meetings. In fact, Dr. Bridgnorth thought that it was shortsighted of any division to squeeze out the junior staff on grounds of their short stay because the posts themselves were permanent and needed representing whoever was filling them. On the other hand, sometimes the immigrant doctors found the system difficult to understand.

Dr. Bridgnorth thought that the divisional chairmen should be paid. The Health Service did not have the right to demand additional effort from people without paying for it, and extra duties should be part of the contract of service. He was concerned that both junior and senior staff contracts contained anomalies, such as the lack of financial recognition for the growing burden of administration and teaching, and that when they were revised many grounds for discontent should be ironed out by making the obligations of both employees and employers clearer and more specific. Senior medical staff should, nevertheless, accept that administration would play an increasing part in their work as they got older in a nationalized health service. The risk of being promoted out of the work one was trained for was not confined to the medical profession, * The name is a pseudonym.
Dr. Bridgnorth said. ${ }^{5}$ A further aspect of the contract, he thought, was that "menial" work in the N.H.S.-if any part of patient care can truly be regarded as menial-was wrongly priced; indeed, it was remarkable what work became consultant work if there was a fee attached to it.

\section{New Developments}

Dr. Bridgnorth was especially interested in the evolution of the new developments within our health services. It was possible, he believed, to influence what would happen from inside a system like Cogwheel, and he himself did not support outside "ginger groups." But, while the divisions remained purely advisory, he was impressed by the subtle manipulations possible-occasionally at the expense of the juniors. For example he suggested that a recommendation from the division, passed by the chairman to the medical executive committee (on which no junior staff sat), and then to the regional hospital board could be readily quashed by the board's asking the chairman privately what he really thought and then turning the proposal down on "professional advice" without giving further reasons. In fact, he insisted, the source of professional advice must be more closely defined before the N.H.S. reorganization was implemented in 1974.

In addition, Dr. Bridgnorth was depressed by the numerical insolubility of the staffing situation. There were, he said, 8,000 full-time consultants. To fill these posts an establishment of only 2,125 junior staff was needed, but there were some 17,000 actual posts and, of course, the service work could not be done with fewer. Of every 100 graduates from the medical schools, 50 were needed in general practice but only 23 entered it by first intent.

His solution to these problems was rather radical: doctors should sell themselves in units of time according to their personal level of skill. There would be a limit on the number of these "medical modules" that could be worked, so that the firm system (only members of the firm looking after the firm's patients) might not survive. Appointments below consultant level would be made to the divisions with contracts for not less than two years. Consultants should still have security of tenure but contrast for defined modules of work. Inumigrant doctors would be admitted only after assessment in their home countries (including all Commonwealth countries) for a probationary year followed by full registration.

\section{Salmon Report}

Turning to the Salmon report, Dr. Bridgnorth thought that Mr. Salmon had been much maligned. He had done what he had been asked to do but had failed to realize that the old ward sister combined both middle (implementing nursing programmes) management and front-line management. It had been wrong to implement Salmon without reviewing the rest of the service, but nurses (like doctors) had to be prepared to accept promotion out of clinical nursing because in both cases administrators who had not proved themselves clinically were despised by the rest of the profession.

Finally, he saw the new area health authorities as political masters giving orders to the lay administration, who would be too unimaginative to resist, and to the Cogwheels, which would resist. Local-authority representation might provide protection against the central government but could interfere locally. In his view the contract of the individual doctor (both senior and junior) would prove the all-important area. If this was right, the system would work; if not, there would be endless dissatisfaction.

Nevertheless, Dr. Bridgnorth would not jettison his Cogwheel division or the system as it had developed in his hospital because he felt that junior doctors' views were now heard 
and heeded. Another senior registrar I talked to in a teaching hospital had also found his medical division most helpful as a forum in which junior opinion on, for example, registrars' clinics could be given cohesion and force. An agenda and minutes were circulated to all members of his division before the monthly open session was held. On this sat registrars and above with a hospital administrator and his secretary (who took the minutes) but no nursing, general-practitioner, or medical officer of health representatives. This was followed by a private consultants-only meeting to discuss staffing and such matters, whose minutes were not circulated. As there was also a medical executive committee, about whose decisions he knew nothing, this Cogwheel system was virtually a three-tier variant.

Yet another senior registrar I talked to worked in one of the three teaching hospitals which have no Cogwheel. He was actively seeking information about it because he had heard that questions were asked about Cogwheel when candidates for consultant posts were interviewed. So it now seems advisable for candidates to find out if the group to which they are applying has a divisional or a medical executive council system, or both.

\section{References}

1 First Report of the foint Working Party on the Organization of Medical Work in Hospitals. London, H.M.S.O., 1967.

2 Organization of the Work of funior Hospital Doctors. London, H.M.S.O., 1971.

${ }^{3}$ All in a Working Day. London, H.M.S.O., 1971

4 Second Report of the foint Working Party on the Organization of Medical in Hospitals. London, H.M.S.O., 1972.

5 The Peter Principle: Why Things Always go Wrong, ed. L. J. Peter and R. Hull, London, Souvenir Press, 1969.

\section{Any Questions?}

We publish below a selection of questions and answers of general interest

\section{Management of Postpubertal Mongols}

What is the best way to manage the behaviour in the postpubertal period of mongol boys living with brothers and sisters at home who have occasional bouts of aggression linked with sexual curiosity? Is vasectomy advisable in these cases?

Although mongols masturbate at least as frequently as nonmongoloids and show some interest in the opposite $\operatorname{sex}^{1}$ the latter is rarely a cause of any anxiety. The penis and scrotum are underdeveloped and the testes are undescended at birth in up to $50 \%$ of mongols ${ }^{2}$ and in about $14 \%$ of mongols at 15 years of age. ${ }^{3}$ Reduced sperm counts have been reported in the semen of adult mongols, ${ }^{4}$ and there is no proved case of a mongol's fathering a child. ${ }^{5}$ There are, therefore, no grounds for recommending vasectomy in mongols.

In general, the management of bouts of aggression linked with sexual curiosity in mongols is little different from that of similar behaviour in children of normal intelligence at the same stage of physical development. A great deal may be done to relieve intrafamily tensions by reassuring parents on the basis of the information given above.

1 Hilliard, L. T., and Kirman, B. H., Mental Deficiency, London, J. A. Churchili, 1957.

2 Benda, C. E., The Child with Mongolism, New York, Grune and Stratton, 1960

3 Øster, J., Mongolism, Copenhagen, Danish Science Press, 1953.

4 Stearns, P. E., Drouland, K. E., and Sahhar, F. H., American fournal of Mental Deficiency, 1960, 65, 37.

5 Penrose, L. S., and Smith, G. F., Down's Anomaly, London, J. A. Churchill, 1966.

\section{Ehlers-Danlos Syndrome}

What is the treatment for the Ehlers-Danlos syndrome? What complications may the syndrome produce in pregnancy?

The Ehlers-Danlos syndrome is an inherited connective tissue weakness. The basic defect is unknown but probably resides at a molecular level. There is no treatment for it. A child of an affected parent has a $50 \%$ chance of inheriting it, regardless of sex.

The syndrome is comprised of several distinct types of varying severity ${ }^{1}$ and the same type runs true in every family. Only in the most severe and very rare "arterial type" is pregnancy contraindicated. In all types close antenatal supervision and early hospitalization for delivery is advisable. Pre- mature birth is common because the fetal membranes share in the general connective tissue weakness and therefore rupture easily leading to the onset of labour. ${ }^{2}$ For the same reason antepartum haemorrhage is a hazard. Joint hypermobility, a component of the syndrome, may be accentuated during gestation to such a degree that patients are unable to walk or suffer spontaneous dislocations. Despite a greater frequency of possible complications many patients reach full term uneventfully and give birth to normal infants. On the credit side mothers with this syndrome do not develop striae gravidarum, because of the easy stretchability of their skin.

1 Barabas, A. P., British Medical fournal, 1967, 2, 612.

1 Barabas, A. P., British Medical fournal, 1967, 2, 612.
2 Barabas, A. P., British Medical fournal, 1966, 2, 682.

\section{Mammary Discs in Baby Girl}

A baby girl of 10 months has palpable mammary discs which persisted after an attack of neonatal mastitis. What, if anything, should be done?

Palpable mammary discs are not abnormal in infancy. The less they are palpated, the better.

\section{Silage Hazards}

$A$ recent report ${ }^{1}$ suggests the more extensive use of silage as a preventive measure in the reduction of farmer's lung. Is there any evidence that silage can carry pulmonary disease?

The only pulmonary disease that has been associated with silage is the so-called "silo-fillers' disease" described in the United States. ${ }^{23}$ This was due to exposure of men engaged in filling silos to nitric oxides, causing an acute illness with pulmonary oedema. No similar cases seem to have been reported in Britain. Evidently, the conditions giving rise to the accumulation of nitric oxides are unusual and should be avoided. The process of silage avoids the danger of exposure to respirable dusts containing the antigens of thermophilic actinomycetes responsible for extrinsic allergic alveolitis.

1 Grant, I. W. B., et al., British Medical fournal, 1972, 1, 530.

2 Delaney, L. T., Schmidt, H. W., and Stroebel, C. F., Mayo Clinic Proceedings, 1956, 31, 189.

3 Ramirez-R, J., and Dowell, A. R., Annals of Internal Medicine,
1971, 74, 569. 